\title{
Implementation of Equilibrium Optimizer Algorithm for MPPT in a wind turbine with PMSG
}

\author{
TUAN NGOC ANH NGUYEN \\ Faculty of Electrical Engineering \\ Industrial University of Ho Chi Minh City \\ Ho Chi Minh City, Vietnam \\ DUY CONG PHAM \\ Faculty of Electrical Engineering \\ Industrial University of Ho Chi Minh City \\ Ho Chi Minh City, VIETnAm \\ NGuYen HuU Chan ThanH \\ Faculty of Aeronautical Electronics Telecommunications Engineering \\ Vietnam Aviation Academy \\ Ho Chi Minh City, VIETNAM \\ ANH NGOC NGUYEN \\ Faculty of Electrical Engineering \\ Industrial University of Ho Chi Minh City \\ Ho Chi Minh City, VIETNAM
}

\begin{abstract}
This paper proposes a new equilibrium optimizer algorithm to extracting the maximum power point tracking which is proposed in permanent magnet synchronous generator under randomly different varying wind speed conditions. It was inspired by controlled volume mass balance modes for estimating dynamic and equilibrium states. The equilibrium optimizer algorithm can mutate the random solving a problem via exploration and exploitation. A particle with its concentration updates its concentration with particular terms. It defined as best-so-far solution, called the equilibrium candidate and the other is equilibrium state, which encourages a particle to global search the domain. The tracking performances of equilibrium optimizer algorithm based trackers firstly are evaluated based on MATLAB software. Results of equilibrium optimizer are compared to two categories of existing optimization methods, including the most well-known genetic algorithm, particle swarm optimization. The performance of the equilibrium optimizer algorithm is analyzed, evaluated and compared based on some key parameters, which are the active power, and turbine power factor under randomly different varying wind speed conditions. Additionally, the obtained results show that the equilibrium optimizer tracker has superiority compared with in all the studied cases.
\end{abstract}

Keywords-Permanent magnet synchronous generator (PMSG); Wind energy conversion systems (WECS); Maximum power point tracking (MPPT); Genetic algorithm (GA); Particle swarm optimization (PSO); Equilibrium Optimizer (EO)

Received: March 14, 2021. Revised: April 12, 2021. Accepted: April 15, 2021. Published: April 21, 2021.

\section{Introduction}

In recent years, electricity generated from renewable energy sources has interested so much because of the negative impacts of global warming and harmful effects of fossil-fuel emissions [1]. In the number of the renewable energy sources includes solar, hydro, geothermal and wind energy, in which wind energy is most interested in because of its competitiveness against 
WSEAS TRANSACTIONS on SYSTEMS and CONTROL

DOI: $10.37394 / 23203.2021 .16 .18$

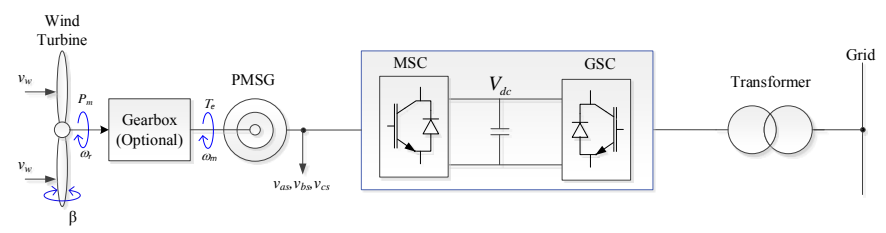

Fig.1 Configuration of the wind generator system using PMSG [2]

conventional sources of energy, in terms of technological advancements, cost reduction, and government incentives and support programs [1-3].

The main configuration of wind energy conversion system (WECS) that includes wind electric generators, power converter, and transformer [2]. The wind electric generator such as the squirrel-cage induction generator (SCIG), wound rotor induction generator (WRIG), doubly-fed induction generator (DFIG), wound rotor synchronous generator (WRSG), and Permanent magnet synchronous generator (PMSG) are used to convert rotational mechanical energy into electric-energy, which have been researched and developed over the last three decades $[1,3]$. Each of them has different advantages and limitations. Among variable-speed wind generators, the PMSG have received increasing attention because of highefficiency, high-reliability, and gearless operation [4].

Until now, a PMSG wind turbine using a full-scale back-to-back (BTB) connected two-level voltage-source converter (2L-VSC), including machine side converter (MSC) and grid- side converter (GSC) are realized by low-voltage insulated gate bipolar transistors (IGBTs) arranged in matrix form. The GSC is designed with higher mega volt-ampere capacity than the MSC $[5,6]$. The DClink provides decoupling between the PMSG and grid. The advantages of it is simple structure, low cost because of the mass production and the transients in the PMSG do not appear on the grid side as illustrated in Fig.1. The main function of the MSC is to completely regulate the generator in terms of speed, active power, power factor, and electromagnetic torque, while the GSC is to regulate the dc-link voltage and the grid reactive power $[7,8]$.

Under variable wind speed conditions, the variablespeed wind turbine should operate with the maximum power point tracking (MPPT) control, which allows it to operate with the good efficiency. In past decades, the MPPT method has been studied and developed in industrial and academic fields includes tip speed ratio (TSR), optimal torque control (OTC) and hill perturb and observe (P\&O). The TSR method requires an anemometer to measure wind speed, which is randomly variable speed. Its limitations are errors in processing measurement, cost and difficulty implementation [9, 10]. The OTC uses lookup table, on which output power turbine depends [11, 12]. The Perturb and observe ( $\mathrm{P} \& \mathrm{O})$ method is simple and does not require an anemometer to measure wind speed. However, the drawbacks are step size, perturbation direction, power loss and low efficiency $[13,14]$.

In the rapidly changing conditions, the tradition MPPT method fail to track MPP and may be entrap in the global maximum [15]. Therefore, these issues have solved by AI based MPPT algorithms that such as Genetic algorithm (GA), Particle swarm optimization (PSO) and equilibrium optimizer (EO) algorithm [16-18]. In this paper, the motivations for choosing the EO algorithm to solve the MPPT problems are as follows.

- First, the EO algorithm is a new algorithm, which has not been applied to find MPPT for PMSG.

- Second, the metaheuristic algorithm has superior performance in solving the tracking MPP problem. Therefore, we want to test the performance of the EO algorithm.

- Finally, the comparison between the EO algorithm and some well-popular, latest and high-performance optimization algorithms. It shows that the proposed EO algorithm achieved the optimal or near-optimal solution with higher efficiency.

This paper is organized as follows: PMSG wind turbine system is explained in detail in Section 2. Section 3 describes the EO algorithm based MPPT method. Simulink verification of a PMSG wind system with the EO algorithm is illustrated in Section 4. Finally, Section 5 concludes this paper.

\section{Wind turbine modeling and problem formulation for maximum power point tracking}

\subsection{Wind turbine model}

The mechanical power harvested by a wind turbine $\mathrm{P}_{\mathrm{m}}$ is expressed as $[3,4]$

$$
P_{m}=\frac{1}{2} \rho \pi R^{2} v_{w}^{3} C_{p}(\alpha, \beta)
$$

where $v_{w}$ is wind velocity, $\rho$ is density of air, $R$ is the blade radius of the wind turbine, $\alpha$ is the tip speed ratio, $\beta$ is the pitch angle, $C_{p}$ is wind turbine power coefficient.

The tip-speed ratio of the turbine is defined by 


$$
\alpha=\frac{\omega_{t}}{v_{w}} R
$$

The curves depend on the blade design and are given by the wind turbine manufacturer

$$
C_{p}(\alpha)=c_{1}\left(\frac{c_{2}}{\alpha_{i}}-c_{3} \beta-c_{4}\right) e^{\left(-\frac{c_{5}}{\alpha_{i}}\right)}+c_{6} \alpha
$$

where $c_{1}=0.5176, c_{2}=116, c_{3}=0.4, c_{4}=5, c_{5}=21, c_{6}=$ 0.0068 and

$$
\alpha_{i}=\left(\frac{1}{\alpha+0.08 \beta}-\frac{0.035}{1+\beta^{3}}\right)^{-1}
$$

In Fig.2 demonstrates clearly the relationship between the turbine power at variable wind speed. The turbine power for a certain wind speed is achievable by a maximum at a certain wind speed that called optimum wind speed. The blue curve is termed by means of optimal tracking curve. For maximum power, the turbine must always operate at an optimal tip speed ratio. This is achievable by controlling the rotational speed of turbine in order that it continuously rotates at the optimum speed [2]. As wind speed variation, the captured wind power relates to the specific operating region within a wind speed range-restricted between connected wind speed $\left(v_{w}\right.$ cut-in) and disconnected wind speed ( $v_{w}$ cut-out). Otherwise, wind turbines must be prevented to operate above connected wind speed ( $v_{w}$ cut-in) or below disconnected wind speed ( $v_{w}$ cut-out) for safety condition.

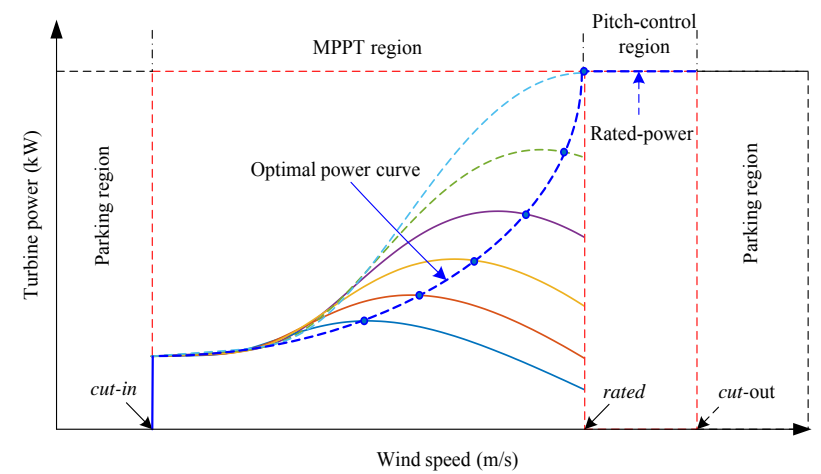

Fig. 2. Wind energy conversion system operating regions

Out of this range, the turbine should not operate for safety of the turbine as well as generator. The rated power $\left(P_{\text {rated }}\right)$ is obtained from the wind turbine at a specific wind speed $\left(v_{\text {rated }}\right)$. Consequently, there are four main operating regions that is classified as follows $[9,11]$. The first and fourth region is below ( $v_{w}$ cut-in) and above ( $v_{w}$ cut-out) respectively that wind turbines must be stopped and disconnected from the grid to avoid the generator implements. The second region is in between ( $v_{w}$ cut-in) and ( $v_{w}$ rated) which a wind turbines controller implements the maximum power point tracking (MPPT) method below rated wind speed to achieve the optimal power during the variable wind speed. The third region is between $\left(v_{w}\right.$ rated) and ( $v_{w}$ cut-out) where the pitch controller is used to limit the mechanical power generation and to minimize the wind turbines mechanically emphasize to keep wind turbines in safe operation. In this paper, the wind speed is surveyed in region 2 (from $3 \mathrm{~m} / \mathrm{s}$ to $12 \mathrm{~m} / \mathrm{s}$ ). Thus, the MPPT method is required to focus on the second region.

\subsection{Dynamic modeling of permanent magnet synchronous generators:}

This section presents the equations of PMSG in the rotor $d q$ reference frame are given as follows [2].

$$
\left\lfloor\begin{array}{l}
u_{d s} \\
u_{q s}
\end{array}\right\rfloor=R_{s}\left\lfloor\begin{array}{l}
i_{d s} \\
i_{q s}
\end{array}\right\rfloor+\frac{d}{d t}\left\lfloor\begin{array}{l}
L_{d s} i_{d s} \\
L_{q s} i_{q s}
\end{array}\right\rfloor+\omega_{r}\left\lfloor\begin{array}{c}
L_{q s} i_{q s} \\
L_{d s} i_{d s}+\lambda_{r}
\end{array}\right\rfloor
$$

The shaft dynamic system and the mechanical torque are started as

$$
T_{e}-T_{L}=J \frac{d \omega_{r}}{d t}-B \omega_{r}
$$

where $u_{d s}$ and $u_{q s}$ are the $d$-axis and $q$-axis stator terminal voltages, respectively; $i_{d s}$ and $i_{q s}$ are respectively the $d$ axis and $q$-axis stator current, $R_{s}$ is the resistance of the stator windings; $\omega_{r}\left(=p \omega_{t}\right)$ is the electrical angular velocity of the rotor; $p$ is the number of pole pairs; $\lambda_{r}$ is the amplitude of the flux linkage; $\lambda_{d s}$ and $\lambda_{q s}$ are the $d$-axis and $q$-axis flux-linkages; $T_{e}$ is the torque; $T_{L}$ is the load torque; $J$ is the inertial; $B$ is the friction coefficient.

In steady-state condition, the equations of PMSG are given by:

$$
\left\lfloor\begin{array}{l}
u_{d s} \\
u_{q s}
\end{array}\right\rfloor=R_{s}\left\lfloor\begin{array}{l}
i_{d s} \\
i_{q s}
\end{array}\right\rfloor+\omega_{r}\left\lfloor\begin{array}{c}
L_{q s} i_{q s} \\
L_{d s} i_{d s}+\lambda_{r}
\end{array}\right\rfloor
$$

The active and reactive powers at generator terminals based on the rotating reference frame, given as

$$
\begin{aligned}
P & =\frac{3}{2}\left(u_{d s} i_{d s}-u_{q s} i_{q s}\right) \\
Q & =\frac{3}{2}\left(u_{d s} i_{q s}-u_{q s} i_{d s}\right)
\end{aligned}
$$

The apparent power is given by

$$
S=\sqrt{P+Q}
$$

\subsection{Problem Formulation}


According to the Eq. (1) at variable wind speed, the turbine power extracted by wind speed which depend on turbine power coefficient $\left(C_{p}\right)$, air density $(\rho)$, the blade radius of the wind turbine $(R)$ and the wind velocity $\left(v_{w}\right)$. However, $\rho$ and $R$ are normally constant. Wind turbine parameters are evaluated based on its model contruction. Futhermore, for a constant blade pitch angle turbine, the turbine power is often dependent on $C_{p}$ that is dependent on rotor speed of wind turbine. Hence, the maximum turbine power can be extracted when $C_{p}$ is optimum. The $C_{p}$ is dependent on the tip speed ratio of turbine $(\alpha)$ as give in Eq. (3) and (4). At particular wind speed, there is only one optimum rotor speed that can be found at $\alpha$ is optimum and therefore $C_{p}$ is optimum to maximize the turbine power.

\section{Equilibrium optimizer algorithm based MPPT}

The power generated $\left(P_{m}\right)$ by wind turbine in Eq. (1) is dependent on $C_{P}, \rho$ and turbine parameters, which are selected based on its design and $\rho$ is a constant value. Therefore, the $P_{m}$ is mainly dependent upon the value of $C_{P}$ and it can be said that the maximum turbine output power $\left(P_{\max }\right)$ can be generated when $C_{P}$ is maximum $\left(C_{p \max }\right)$. If the wind turbine is operated at $C_{p \max }, \alpha$ will be optimum as observed in Eqs. (3) and (4), and from Eq. (2) so the rotor speed will be maximum. Thus, it can also be observed from Fig. 2 the output turbine power can be maximized by regulating the rotor speed to its maximum value at each various wind speed.

\subsection{An overview of Equilirium Optimizer Algorithm}

The EO is a new physical-based optimization algorithm that is proposed in 2019 by Faramarzi et al [16, 17]. The EO algorithm can mutate the random solving a problem via exploration and exploitation. A particle with its concentration is operated similar a solution and position in the PSO algorithm and update its concentration with particular terms. It defined as best-sofar solution, called the equilibrium candidate and the other is equilibrium state, which encourages particle to global search the domain.

A first-order ordinary differential equation expressing the generic mass-balance equation [18]

$$
E=Q C_{\text {equ }}-Q C+G
$$

where $C$ is the concentration of particles in the control volume, $E$ is the rate of change in mass in the control volume, $Q$ is the volumetric flow rate into and out of the control volume, $C_{e q u}$ is the concentration of particles inside the control volume at an equilibrium state without generation, $G$ is the mass generation rate inside the control volume.
The basic steps of the EO algorithm are performed through the following steps.

- Initialization and function evaluation

Similar to meta-heuristic algorithms, EO start the optimization process by using the initial population. The initial concentration is constructed based on the number of particles and dimensions with uniform random initialization in the search space as follows $[14,15]$

$$
C_{i}^{\text {initial }}=C_{\min }+\operatorname{rand}_{i}\left(C_{\max }-C_{\min }\right) ; i=1,2 . ., n
$$

where $C_{i}^{\text {initial }}$ is the initial concentration vector of $i^{\text {th }}$ particles, $C_{\min }$ and $C_{\max }$ are the minimum and maximum value of dimensions, $\mathrm{rand}_{\mathrm{i}}$ is a random number in $[0,1]$, and $\mathrm{n}$ is the total number of particles.

- Equilibrium pool and candidates $\left(C_{e q}\right)$

The equilibrium concentration is defined as the final convergence state of the EO algorithm, which constructs a vector called the equilibrium pool and provides equilibrium candidate particles. Based on experiments, five candidate particles of the equilibrium pool were determined. Four of it are the optimal particles identified in the whole optimization process, and the other one is the arithmetic mean of the above four particles. It is described as follows.

$$
\vec{C}_{\text {equ.pool }}=\left\{\vec{C}_{\text {equ (1) }}, \vec{C}_{\text {equ (2) }}, \vec{C}_{\text {equ (3) }}, \vec{C}_{\text {equ (4) }}, \vec{C}_{\text {equ (ave) }}\right\}
$$

In each iteration, each particle updates randomly its concentration with the same probability.

- Exponential term $(F)$

The main concentration updating rule is the exponential term $(F)$

$$
\vec{F}=e^{-\vec{\lambda}\left(t-t_{0}\right)}
$$

where $\lambda$ is assumed to be a random vector in the interval of $[0,1]$ and $t$ is a function of iteration that decreases with the number of iterations.

$$
t=\left(1-\frac{\text { Iter }}{\text { Max_iter }}\right)^{\mathrm{a}_{2}\left(\frac{\text { iter }}{\text { Max_iter }}\right)}
$$

where Iter and Max_iter present the current and the maximum number of iterations, respectively, and $a_{2}$ is a constant value used to manage exploitation ability. The calculation of $t_{0}$ is as follows

$$
\vec{t}_{0}=\frac{1}{\vec{\lambda}} \ln \left(-a_{1} \operatorname{sign}(\vec{r}-0.5)\left(1-e^{-\vec{\lambda} t}\right)\right)+t
$$

where $a_{1}$ is a constant value used to manage exploration ability. In the literature, $a_{1}$ and $a_{2}$ are equal to 2 and 1 . $\operatorname{sign}(\vec{r}-0.5)$ indicates the direction of exploration and exploitation.

The substitution of Eq. (16) into Eq. (14): 


$$
\vec{F}=a_{1} \operatorname{sign}(\vec{r}-0.5)\left(e^{-\vec{\lambda} t}-1\right)
$$

- Generation rate $(G)$

The generation rate $(G)$ enables the $\mathrm{EO}$ algorithm to provide accurate solutions by improving the exploitation phase.

$$
\vec{G}=\vec{G}_{0} e^{-\vec{k}\left(t-t_{0}\right)}
$$

where $G_{0}$ is the initial value and $k$ is a decay constant $(k=$ $\lambda)$. Therefore, the final expression of the generation rate is as follows:

$$
\vec{G}=\vec{G}_{0} e^{-\vec{k}\left(t-t_{0}\right)}=\vec{G}_{0} \vec{F}
$$

where

$$
\begin{aligned}
& \vec{G}=\overrightarrow{G C P}\left(\overrightarrow{C_{\text {equ }}}-\vec{\lambda} \vec{C}\right) \\
& \overrightarrow{G C P}= \begin{cases}0.5 r_{1} & r_{2} \geq G P \\
0 & r_{2}<G P\end{cases}
\end{aligned}
$$

where $r_{1}$ and $r_{2}$ are random numbers between $[0,1]$, and $\overrightarrow{G C P}$ indicates the generation parameter, which contributes to the updating process. In Eq. (21) GP (GP= 0.5 ) is called the generation probability, and its role is to achieve a good balance between exploration and exploitation. Finally, the updating rule of EO is as follows.

$$
\vec{C}=\vec{C}_{e q u}+\left(\vec{C}-\vec{C}_{e q u}\right) \vec{F}+\frac{\vec{G}}{\vec{\lambda} V}(1-\vec{F})
$$

where $V$ is considered as unit.

The first term in Eq. (22) is an equilibrium concentration, where the second and third terms represent the variations in concentration [16]

\subsection{Flowchart of EO}

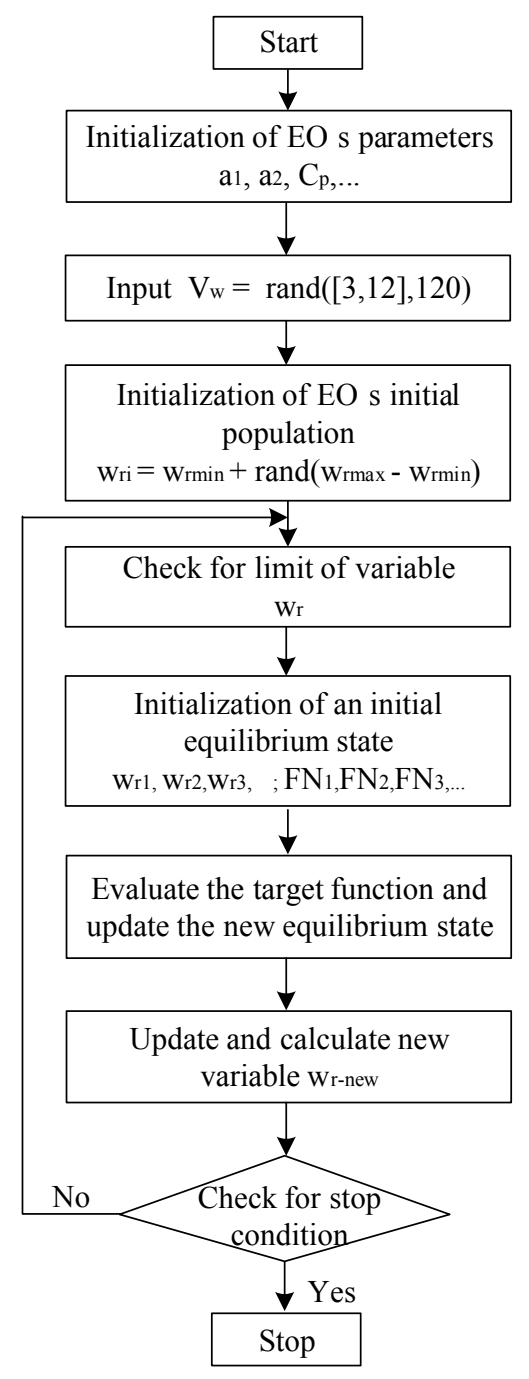

Fig. 3. Flowchart of equilibrium optimizer

\section{Simulation results}

The simulation for evaluating the performance of the EO algorithm based the MPPT method applied to PMSG that is implemented using MATLAB/Simulink. Furthermore, its optimum rotor speed is sought by the EO algorithm based MPPT method, at where generated maximum turbine power. In this paper, the research and consideration of EO algorithm based MPPT method are performed on the case of variable wind speed data, which is selected randomly between 3 and $12 \mathrm{~m} / \mathrm{sec}$ as illustrated in Fig.4. Some of the parameters of the generator and turbine that are used for the simulation are shown in Tables 1 and 2. The simulation parameters of the EO algorithm is illustrated in Tables 3. In this paper, the comparison has been carried out by evaluation and analysis the turbine power coefficient, turbine power, and the relationship between turbine powers at variable rotor speed that is implemented by EO algorithm with the other intelligent algorithms such as Genetic algorithm (GA) and Particle swarm optimization (PSO) algorithm. 
The turbine power coefficient $\left(C_{p}\right)$ obtained by each algorithm based MPPT method is illustrated in Fig.5. It can be showed that, when the wind speed varies quickly, the $C_{p}$ in EO algorithm, which is not oscillation and remains almost constant at 0.48 while GA algorithm is unstable and widely oscillation. Furthermore, the waveform of $C_{p}$ in the PSO algorithm that is unstable too and oscillation but it is low. Simulation results for peak value of wind speed during $0-120 \mathrm{sec}$ in Fig.5 have been zoomed for clearly differentiate the results obtained between EO- and PSO algorithm based MPPT method. The relationship between the turbine powers at variable rotor speed obtained by each algorithm is demonstrated in Fig.6. It can be seen that, when the wind speed varies is based on Eq. (1), (2) the maximum turbine power in EO algorithm based MPPT method has the high stability and tracks the MPP very efficiently while the GA- and PSO algorithm deviate from the MPP so it has stability lower and tracked worse. In addition, simulation results have been zoomed for clearly differentiate the results obtained between EO- and PSO algorithm for turbine power when rotor speed during $1.735-1.755 \mathrm{rad} / \mathrm{s}$. It can be seen that under variable wind speed, the turbine power in EO algorithm, which has the highest value while GA algorithm is the lowest, and PSO algorithm is moderate which is illustrated in Fig.7. Furthermore, simulation results for peak value of turbine power during 31-33 sec in Fig. 7 have been zoomed for clearly differentiate the results obtained between EO- and PSO algorithm. In addition, as illustrated in Fig.8,9, the turbine power in EO algorithm is always higher the turbine power in GA- and PSO algorithm at any variable wind speed data, which is selected randomly between 3 and $12 \mathrm{~m} / \mathrm{sec}$. According to Fig. 10 the turbine power with 100 iterations in EO algorithm, which is not oscillation and remains almost constant at $4.5204 \mathrm{e}-07$ while GA- and PSO algorithm is unstable and widely oscillation. The standard deviation of EO algorithm has the smallest is $1.3343 \mathrm{e}-18$ while the standard deviation of GA has the highest value is $7.5363 \mathrm{e}-$ 09 and the standard deviation of PSO has moderate value is $1.7716 \mathrm{e}-12$ that is illustrated in table 4 .

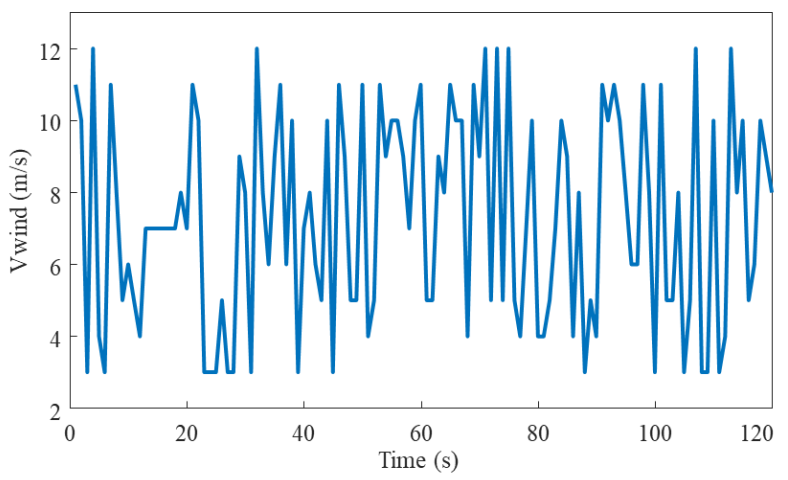

Fig.4. Wind speed profile

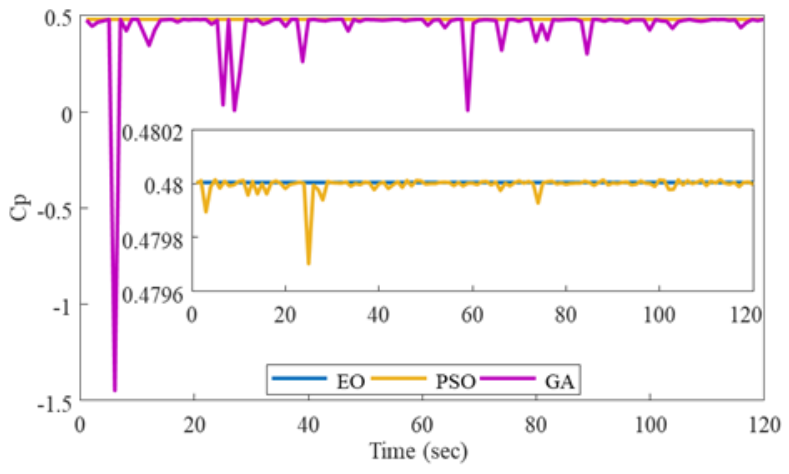

Fig.5. Turbine power coefficient in three algorithms

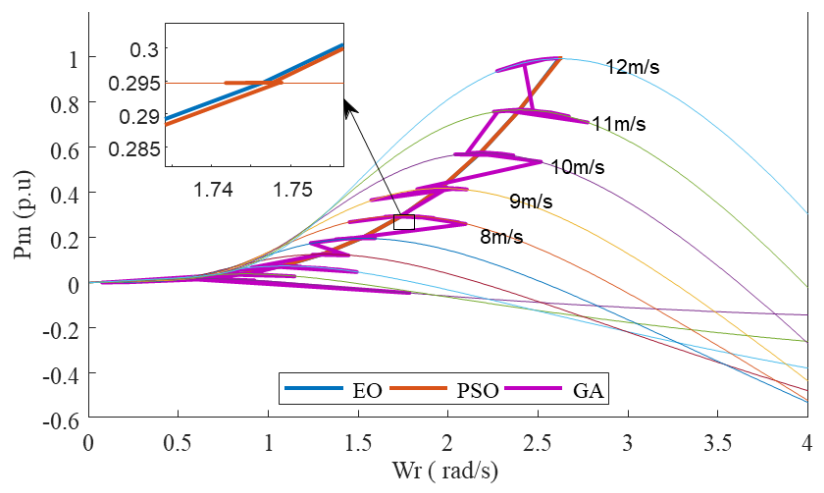

Fig.6. Turbine power and rotor speed in three algorithms

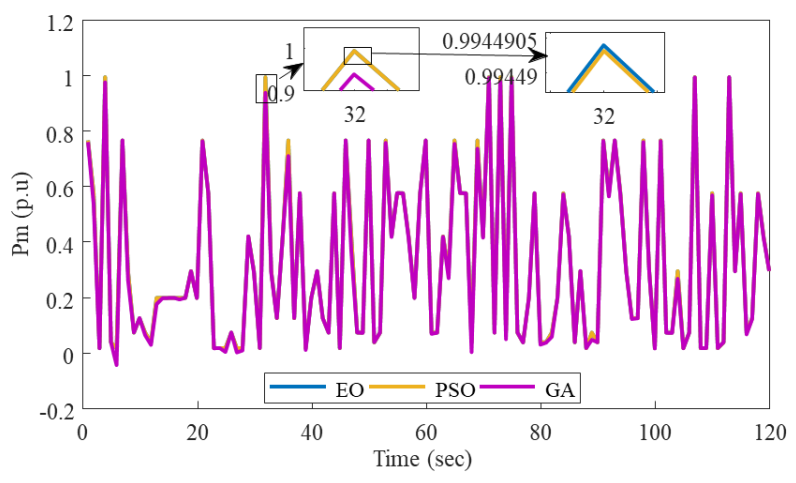

Fig.7. Turbine power in three algorithms

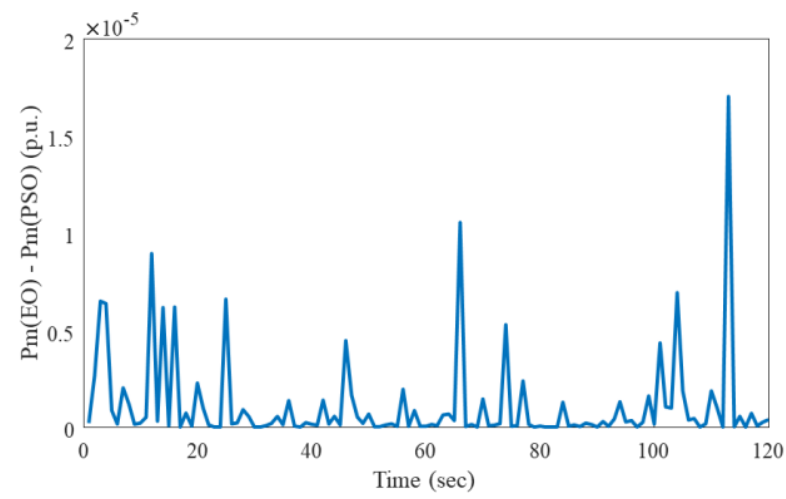

Fig.8. Turbine power difference in case EO and PSO 
WSEAS TRANSACTIONS on SYSTEMS and CONTROL

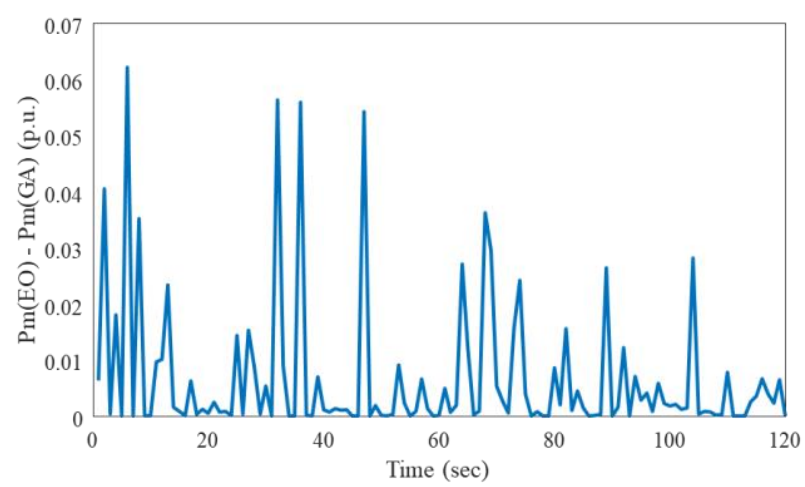

Fig.9. Turbine power difference in case EO and GA

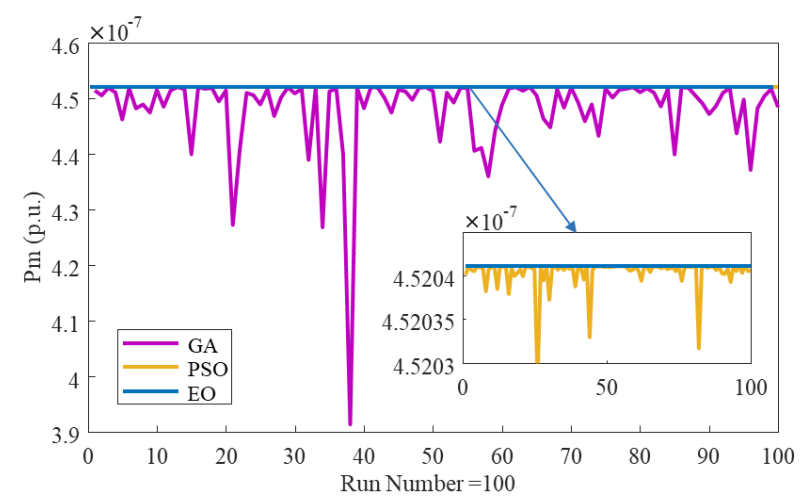

Fig.10. Algorithm stability through standard deviation

TABLE 4: COMPARISON STABILITY OF THREE ALGORITHMS

\begin{tabular}{|l|c|c|c|}
\hline Algorithms & EO & PSO & GA \\
\hline $\mathrm{P}_{\min }$ (p.u) & $4.5204 \mathrm{e}-07$ & $4.5203 \mathrm{e}-07$ & $3.9144 \mathrm{e}-07$ \\
\hline $\mathrm{P}_{\text {average }}$ (p.u) & $4.5204 \mathrm{e}-07$ & $4.5204 \mathrm{e}-07$ & $4.4813 \mathrm{e}-07$ \\
\hline $\mathrm{P}_{\max }$ (p.u) & $4.5204 \mathrm{e}-07$ & $4.5204 \mathrm{e}-07$ & $4.5204 \mathrm{e}-07$ \\
\hline $\begin{array}{l}\text { Standard } \\
\text { deviation }\end{array}$ & $1.3343 \mathrm{e}-18$ & $1.7716 \mathrm{e}-12$ & $7.5363 \mathrm{e}-09$ \\
\hline
\end{tabular}

As the above analysis, it indicates that the EO algorithm based MPPT method acquires the best turbine power among other algorithms considered in this paper. It has a higher success rate than GA- and PSO algorithm based MPPT method since it does searching and finding the MPP more efficiently. Consequently, EO algorithm is simple, flexible and also more efficient.

\section{Conclusion}

In this paper, the EO algorithm has been applied successfully to find MPPT for PMSG and has superior performance in solving the fail to track MPP in the rapidly changing conditions and may be entrap in the global maximum. The performance of EO optimization algorithm based on MPPT method is designed, analyzed and evaluated. The simulation results confirm that EO algorithm have high accuracy and stability in tracking the MPP. From the above analysis, it may be concluded that EO algorithm is very effective for finding out the MPP to improve the efficiency of PMSG in WECS. Future work concerns research in Hardware in Loop for MPPT using evolutionary algorithms.

\section{Acknowledgments}

The authors would like to thank Industrial University of Ho Chi Minh City, Vietnam for providing the funding for this research.

\section{Appendix}

TABLE 1: TURBINE PARAMETERS USED IN SIMULATION [2]

\begin{tabular}{|l|c|l|}
\hline Description & Parameter & \multicolumn{1}{|c|}{ Value } \\
\hline Transparent power & $S_{n}$ & $2.2 \mathrm{MW}$ \\
\hline Nominal current & $I_{n}$ & $2606 \mathrm{~A}$ \\
\hline Nominal Voltage & $u_{n}$ & $690 \mathrm{~V}$ \\
\hline dc-link voltage & $V_{d c}$ & $1200 \mathrm{~V}$ \\
\hline Nominal rotating speed & $\omega_{m}$ & $2.355 \mathrm{rad} / \mathrm{s}$ \\
\hline Number of poles & $Z_{p}$ & $26 \mathrm{~N} . \mathrm{m}$ \\
\hline Nominal moment & $T_{e}$ & $934.2 \mathrm{kNm}$ \\
\hline Viscous damping & $B$ & $0.004 \mathrm{Nms}$ \\
\hline Stator phase resistance & $R_{s}$ & $0.8 \mathrm{e}-3 \Omega$ \\
\hline Stator phase inductance & $L_{s}$ & $1.67 \mathrm{mH}$ \\
\hline Flux linkage & $\lambda_{r}$ & $9.18 \mathrm{~Wb}$ \\
\hline Inertia of turbine rotor & $J_{n}$ & $0.5 \mathrm{e} 6 \mathrm{~kg} . \mathrm{m}^{2}$ \\
\hline
\end{tabular}

TABLE 2. GENERATOR PARAMETERS USED IN SIMULATION [2]

\begin{tabular}{|l|c|l|}
\hline \multicolumn{1}{|c|}{ Description } & Parameter & \multicolumn{1}{c|}{ Value } \\
\hline Rated power & $P_{n}$ & $2 \mathrm{MW}$ \\
\hline Nominal rotating speed & $\omega_{m}$ & $2.355 \mathrm{rad} / \mathrm{s}$ \\
\hline Inertia of generator rotor & $J_{m}$ & $0.25 \mathrm{e} 3 \mathrm{~kg} . \mathrm{m}^{2}$ \\
\hline Blades length & $R$ & $37.1 \mathrm{~m}$ \\
\hline Base wind speed & $v_{w}$ & $12 \mathrm{~m} / \mathrm{s}$ \\
\hline
\end{tabular}

TABLE 3. EO PARAMETERS USED IN SIMULATION

\begin{tabular}{|l|c|}
\hline \multicolumn{1}{|c|}{ Parameter } & Value \\
\hline Particle number of a generation, Npop & 50 \\
\hline Maximum number of generations, itermax & 50 \\
\hline
\end{tabular}


WSEAS TRANSACTIONS on SYSTEMS and CONTROL DOI: $10.37394 / 23203.2021 .16 .18$

\begin{tabular}{|l|c|}
\hline Constant used to manage exploration ability $\left(\mathrm{a}_{1}\right)$ & 2 \\
\hline Constant used to manage exploitation ability $\left(\mathrm{a}_{2}\right)$ & 1 \\
\hline The generation probability $(\mathrm{GP})$ & 0.5 \\
\hline
\end{tabular}

References:

[1] Venkata Yaramasu, Bin Wu, Paresh C. Sen, Samir Kouro, and Mehdi Narimani, High-power wind energy conversion systems: state-of-the-art and emerging technologies, Proceedings of the IEEE Vol.103, No.5, May 2015.

[2] Viktor Perelmuter, Renewable energy systems: Simulation with Simulink and SimPowerSystems, CRC Press Published November 23, 2016.

[3] Mario J. Duran, Federico Barrero, Senior Member, IEEE, Ana Pozo-Ruz, Francisco Guzman, José Fernandez, and Hugo Guzman, Understanding power electronics and electrical machines in multidisciplinary wind energy conversion system courses, IEEE Transactions on Education, Vol. 56, No. 2, May 2013.

[4] Henk Polinder, Jan Abraham Ferreira, Bogi Bech Jensen, Asger B. Abrahamsen, Kais Atallah, Richard A. McMahon, Trends in wind turbine generator systems, IEEE journal of emerging and selected topics in power electronics, Vol. 1, No. 3, September 2013.

[5] Ramji Tiwari, N. Ramesh Babu, Recent developments of control strategies for wind energy conversion system, Renewable and Sustainable Energy Reviews 66 (2016) 268-285.

[6] Venkata Yaramasu, Apparao Dekka, Mario J. Durán, Samir Kouro, Bin Wu, PMSG - based wind energy conversion systems: survey on power converters and controls, IET Electric Power Appl., 2017, Vol. 11, Iss. 6, pp. 956-968.

[7] Mohsen Rahimi, Mathematical modeling, dynamic response analysis, and control of PMSG- based wind turbines operating with an alternative control structure in power control mode, Int Trans Electr Energ Syst. 2017.

[8] Hua Ye, Bo Yue, Xuan Li and Kai Strunz, Modeling and simulation of multi - scale transients for PMSG - based wind power systems, Wind Energ. 2017; 20:1349-1364.

[9] Abdullah M.A., Yatim A.H.M., Tan C.W., Saidur R, A review of maximum power point tracking algorithms for wind energy systems, Renewable and Sustainable Energy Reviews 16 (2012) 3220-3227.

[10] Abdel-Raheem Youssef, Ahmed I.M. Ali, Mahmoud S.R. Saeed, Essam E.M. Mohamed, Advanced multisector $\mathrm{P} \& \mathrm{O}$ maximum power point tracking technique for wind energy conversion system, Electrical Power and Energy Systems 107(2019) 8997.

[11] Hossam H.H. Mousa, Abdel-Raheem Youssef, I. Hamdan, Maqusood Ahamed and Essam E.M. Mohamed, Variable step size P\&O MPPT algorithm for optimal power extraction of multi-phase PMSG based wind generation system, Electrical Power and Energy Systems 108 (2019) 218 - 231.

[12] Mekalathur B. Hemanth Kumar, Balasubramanian Saravanan, Padmanaban Sanjeevikumar and Frede Blaabjerg, Review on control techniques and methodologies for maximum power extraction from wind energy systems, IET Renewable Power Generation, September 2018.

[13] Hossam H.H. Mousa, Abdel-Raheem Youssef, I. Hamdan, Maqusood Ahamed and Essam E.M. Mohamed, Performance Assessment of Robust P\&O Algorithm Using Optimal Hypothetical Position of Generator Speed, IEEE, Volume 9,2021.

[14] A. Safari and S. Mekhilef, Simulation and hardware implementation of incremental conductance MPPT with direct control method using cuk converter, IEEE Trans. Ind. Electron., Vol. 58, No. 4, pp. 1154 1161, Apr. 2011.

[15] T. Esram, P.L. Chapman, Comparison of Photovoltaic Array Maximum Power Point Tracking Techniques, IEEE Transaction on Energy Conversion, Vol.22, No.2, pp.439-449, June 2007.

[16] Afshin Faramarzi, Mohammad Heidarinejad, Brent Stephens, Seyedali Mirjalili, Equilibrium optimizer: A novel optimization algorithm, Sciendirect Volume 191, 5 March 2020, 105190.

[17] Sanam Agnihotri, Apoorwa Atre and H. K. Verma, Equilibrium optimizer for solving Economic Dispatch Problem, 2020 IEEE 9th Power India International Conference (PIICON).

[18] A. A. Abou El Ela, M. A. Abido, and S. R. Spea, Optimal power flow using differential evolution algorithm, Electr. Power Syst. Res., Vol. 80, No. 7, pp.878-885,2010.

\section{Creative Commons Attribution License 4.0 (Attribution 4.0 International, CC BY 4.0)}

This article is published under the terms of the Creative Commons Attribution License 4.0

https://creativecommons.org/licenses/by/4.0/deed.en_US 